Published in final edited form as:

J Pain. 2013 December ; 14(12 0): T63-74.e1-6. doi:10.1016/j.jpain.2013.06.007.

\title{
Pain Sensitivity and Autonomic Factors Associated with Development of TMD: the OPPERA Prospective Cohort Study
}

\author{
Joel D. Greenspan ${ }^{1}$, Gary D. Slade ${ }^{2,3,4}$, Eric Bair ${ }^{4,5,6}$, Ronald Dubner ${ }^{1}$, Roger B. Fillingim ${ }^{7}$, \\ Richard Ohrbach ${ }^{8}$, Charlie Knott ${ }^{9}$, Luda Diatchenko ${ }^{4,6,10}$, Qian Liu ${ }^{5}$, and William Maixner ${ }^{4,6}$ \\ ${ }^{1}$ Department of Neural and Pain Sciences, and Brotman Facial Pain Center, University of \\ Maryland School of Dentistry, Baltimore, MD \\ ${ }^{2}$ Department of Dental Ecology, University of North Carolina at Chapel Hill, Chapel Hill, NC \\ ${ }^{3}$ Department of Epidemiology, University of North Carolina at Chapel Hill Chapel Hill, NC \\ ${ }^{4}$ Center for Neurosensory Disorders, University of North Carolina at Chapel Hill Chapel Hill, NC \\ ${ }^{5}$ Department of Biostatistics, University of North Carolina at Chapel Hill Chapel Hill, NC \\ ${ }^{6}$ Department of Endodontics, University of North Carolina at Chapel Hill Chapel Hill, NC \\ ${ }^{7}$ Department of Community Dentistry \& Behavioral Science, University of Florida, Gainesville, FL \\ ${ }^{8}$ Department of Oral Diagnostic Services, University at Buffalo, Buffalo, NY \\ ${ }^{9}$ Battelle Memorial Institute, Durham, NC \\ ${ }^{10}$ Carolina Center for Genome Sciences, University of North Carolina at Chapel Hill, Chapel Hill, \\ NC
}

\section{Abstract}

Multiple studies report that individuals with chronic temporomandibular disorder (TMD) have enhanced sensitivity to experimental pain. Additionally, chronic TMD cases show altered autonomic function, including elevated heart rate and reduced heart rate variability. However, causal inferences regarding the association between TMD and pain sensitivity and autonomic function cannot be drawn from these cross-sectional observations. The prospective OPPERA study examines whether measures of pain sensitivity or cardiac autonomic function provide predictive value in TMD incidence. A cohort of 2,737 initially TMD-free people was followed for up to 5.2 years, during which time 260 developed first-onset TMD. Fourteen of 39 experimental

(C) 2013 The American Pain Society. Published by Elsevier Inc. All rights reserved.

Please address all correspondence to: Joel Greenspan, University of Maryland, School of Dentistry, 650 W. Baltimore Street, 8 th Floor South, Baltimore, Maryland 21201, Ph: 410-706-7090, FAX: 410-706-0865, jgreenspan@ umaryland.edu.

This work was done at: University of North Carolina at Chapel Hill, NC; University at Buffalo, NY; University of MarylandBaltimore, MD; University of Florida, FL; and Battelle Memorial Institute, NC.

Disclosures

This work was supported by NIH grant U01DE017018. The OPPERA program also acknowledges resources specifically provided for this project by the respective host universities: University at Buffalo, University of Florida, University of Maryland-Baltimore, and University of North Carolina-Chapel Hill. Roger Fillingim and Gary Slade are consultants and equity stock holders, and William Maixner and Luda Diatchenko are cofounders and equity stock holders in Algynomics, Inc., a company providing research services in personalized pain medication and diagnostics. Richard Ohrbach, Joel Greenspan, Charles Knott, Ronald Dubner, Eric Bair, and Qian Liu declare that they have no conflicts of interest.

Publisher's Disclaimer: This is a PDF file of an unedited manuscript that has been accepted for publication. As a service to our customers we are providing this early version of the manuscript. The manuscript will undergo copyediting, typesetting, and review of the resulting proof before it is published in its final citable form. Please note that during the production process errors may be discovered which could affect the content, and all legal disclaimers that apply to the journal pertain. 
pain measures produced significant hazard ratios, such that greater pain sensitivity was associated with greater TMD incidence. A single autonomic measure - heart rate at rest - was also associated significantly with greater TMD incidence. In contrast, using the same measures of pain sensitivity and cardiac autonomic function, we previously reported a larger group of variables that was significantly associated with chronic TMD in the OPPERA case-control study. Future studies should investigate whether premorbid pain sensitivity or autonomic function more specifically predicts risk of developing chronic TMD than first-onset TMD.

\section{Keywords}

Quantitative Sensory Testing; Temporomandibular Joint Disorders; orofacial pain; heat pain; pressure pain; cardiovascular measures

\section{Introduction}

Considerable evidence has accumulated showing that physiological factors, including altered pain sensitivity and autonomic dysfunction, are associated with several chronic pain conditions, including temporomandibular disorder (TMD) ${ }^{15}$. Specifically, in case-control studies, individuals with chronic TMD have been found to have greater pain sensitivity to experimental pain than TMD-free controls, even when experimental pain was evaluated at asymptomatic body sites $7,16,17,23,26$. This enhanced pain sensitivity has been documented for different pain domains (i.e., both cutaneous and deep tissue evoked pain), and different types of measures (i.e., threshold and suprathreshold measures of pain). Additionally, individuals with chronic TMD have been found to have dysregulated autonomic system function, including higher cardiac output and lower total vascular resistance ${ }^{11}$, as well as higher cardiosympathetic tone both at rest and under stress ${ }^{18}$.

While such case-control studies are informative about chronic pain associations, they cannot address the critical causal questions. Specifically, does the heightened pain sensitivity and autonomic dysregulation precede the development of chronic TMD, or do these characteristics develop as a consequence of having TMD for some period of time? Evidence to address these questions comes from prospective cohort studies that first measure pain sensitivity and autonomic function in people without TMD, and then monitor them prospectively to document those who develop TMD. To our knowledge, only one such study has been reported. The study found that heightened pain sensitivity was a predictive factor for TMD among a cohort of 171 women followed for three years ${ }^{25}$.

The current report describes results from the first large-scale prospective cohort study of TMD, evaluating the contribution of enhanced pain sensitivity and autonomic dysregulation to the incidence of TMD. The aim of the study described here was to identify which, if any, measures of experimental pain sensitivity and autonomic function would serve to predict the development of painful TMD, when assessed prior to TMD onset. The studies reported here are a part of the larger parent project "Orofacial Pain: Prospective Evaluation and Risk Assessment" (OPPERA) which also included a previously reported case-control study, ${ }^{5}$ where heightened pain sensitivity and autonomic dysregulation were found to be associated with chronic TMD.

\section{Materials and Methods}

This section summarizes the study methods that are explained in detail in Supplementary Materials section and elsewhere in this volume ${ }^{2}$. Study participants were verbally informed of the study and provided signed consents. The OPPERA project was reviewed and 
approved by institutional review boards at each of four study sites and at the data coordinating center, Battelle Memorial Institute.

\section{Study design, setting and participants}

This paper reports findings from the OPPERA prospective cohort study of 2,737 people who were enrolled in 2006-08 and followed for up to 5.2 years, during which time 260 people developed painful temporomandibular disorder (TMD). When enrolled, the sample of community-based volunteers at four study U.S. sites was aged 18-44 years and did not have TMD when examined using OPPERA's adaptation of a restricted set of Research Diagnostic Criteria for TMD (RDC/TMD) ${ }^{19}$. At enrollment, study participants also completed questionnaires, autonomic function was measured, sensitivity to sensory stimuli was evaluated, and a blood sample was collected for genotyping.

This paper focuses on baseline measurements of pain sensitivity and autonomic function, which have been described previously. ${ }^{7,18}$ Detailed specifications of measurement protocols can be found in the supplementary material accompanying this article. Briefly, pain sensitivity tests encompassed three stimulus modalities: 1) pressure pain thresholds (PPT) on five body sites - overlying the masseter muscle, temporalis muscle, the temporomandibular joint, the trapezius muscle, and the lateral epicondyle; 2) cutaneous mechanical pain sensitivity, involving measures of threshold, ratings of suprathreshold stimuli, temporal summation, and aftersensations, assessed on the hand; and 3) heat pain sensitivity, involving threshold, tolerance, ratings of suprathreshold stimuli, temporal summation, and aftersensations, assessed on the forearm. Autonomic measures included arterial blood pressure, heart rate, and heart rate variability measures taken under rest and during two provocative conditions: an orthostatic challenge and a Stroop protocol.

At three-monthly intervals after enrollment, study participants were asked to complete a screening questionnaire that asked about TMD pain symptoms. Those reporting symptoms were invited to study clinics for a follow-up examination that determined presence or absence of TMD using the same adaptation of RDC/TMD criteria. Specifically, 260 incident cases satisfied two criteria for TMD: (1) symptoms of orofacial pain reported for 25 days/ month; and (2) examiner findings of TMD myalgia, arthralgia, or both.

\section{Statistical Analysis}

For descriptive purposes, the average annual incidence of first-onset TMD was calculated as the number of people with first-onset TMD divided by the sum of follow-up intervals. To test hypotheses about associations between baseline characteristics and TMD incidence, univariate hazard ratios were first computed using Cox proportional hazard regression. For each baseline risk factor, scores were transformed to unit-normal deviates (mean $=0$, standard deviation=1). Unit-normal deviates were reversed (i.e., the sign was changed) for measures of pain threshold, so that higher values represented greater sensitivity to the stimulus. Hazard ratios were computed both with adjustment for study site and with additional adjustment for demographics (age, gender, race/ethnicity and lifetime US residence). Hazard ratios were also computed using multiple imputation to account for two sources of potential bias associated with: a) non-examination of 243 people with symptoms; and b) a higher-than expected rate of TMD classification for one examiner who conducted 75 examinations. Collectively, these are described below as results that are "imputed for examinations that were not done as intended".

A principal limitation of this univariate approach is that since some of the individual variables are correlated, those associations will not be independent. Furthermore, hazard ratios were considered nominally significant if the $95 \%$ CI did not include the value of 1.0. 
This would equate to a criterion of $\mathrm{p}<0.05$. Other group differences were also noted as significant at $\mathrm{p}<0.05$. While this criterion does not account for multiple testing, the statistical results are presented in a full manner in the tables, to allow the reader to consider the significance under other criteria. Note that if we were to apply a conventional Bonferroni adjustment for the 39 variables reported in Tables 1 and 2, the critical P-value would be $\mathrm{p}<0.00128$.

The second stage of the analysis involved a series of multivariable Cox regression models in which the entered variables were derived from a principal component analysis (PCA). The PCAs, performed separately for QST and autonomic data, as reported previously, were performed in order to reduce the number of variables by virtue of being highly correlated. The goal of Cox multivariable modeling was to assess independent contributions of each principal component to TMD incidence. In this context, an "independent" contribution is one which is not confounded by the other components. Hazard ratios for the associations were estimated in a single Cox regression model that included all components as predictor variables, together with study site and socio-demographic characteristics. First, all factors were entered into a multivariable Cox regression model simultaneously in order to identify the factors that independently predicted development of TMD. Second, interactions of each factor score with demographic variables in predicting TMD development were examined in Cox regression models. Third, all possible two-way interactions between factor scores were examined in regression models. This more traditional multivariable approach allowed us to examine whether these components, either alone or via interactions with other factors, predicted TMD onset.

The final stage of the analysis involved an alternative multivariable approach, random forest modeling, to analyze potential contributions of all variables, not merely the reduced set of principal components. This cutting-edge analytic approach was used to achieve two goals: a) to identify the most important risk factors for first-onset TMD at the individual variable level; and b) to generate plots depicting adjusted association between each variable and TMD incidence, with adjustment for the effects of other variables and with latitude in generating the plots that permitted departure from a straight-line association. Random forest modeling represents a machine learning technique based on a series of decision tree models ${ }^{10}$. Decision trees predict outcomes by recursively partitioning predictor variables, and these trees are superior to regression-based models in identifying non-linear effects and handling missing data. Random forests improve the accuracy of individual decision trees by averaging over a series of decision trees. ${ }^{8}$ In recent years, random forests have been increasingly applied to classification problems in biomedical research, including predicting several pain related outcomes ${ }^{9,22,28}$. The random forest model was used to compute the expected rate of first-onset TMD that would be observed at several values of the variable after averaging over the values of all other variables in the model. Partial dependence plots were then generated and LOESS smoothing was used to help visualize the association ${ }^{12}$.

These two multivariable strategies were selected in favor of other approaches for several reasons. The first strategy builds on findings from our baseline case-control studies which identified meaningful factors from among the multitude of QST and autonomic measures used in OPPERA ${ }^{7}$. The relatively small number of factors meant that all of them could be used in a single Cox regression model, thereby adjusting for potential confounding effects between constructs. This avoided arbitrary choices and potential bias that occur commonly when stepwise procedures and related variable selection methods are used to select a restricted set of potential confounders ${ }^{6}$. However, regression using principal component scores can mask effects on TMD incidence of single items that do not fit will within the components. Furthermore, variable selection methods that are needed to exclude variables from a large candidate set of predictors do not provide information about the excluded 
variables. Also, variable selection regression methods produce $\mathrm{p}$-values and confidence intervals that are less reliable ${ }^{1,6}$. Thus, a random forest model was used to address these objectives $^{3,10}$.

\section{Results}

The cohort of 2,737 initially-TMD-free people was followed for a total of 7,404 personyears (median $=2.8$ years per person), during which time 260 people developed first-onset TMD, yielding an annual incidence rate of $3.5 \%$. For those 260 incident cases, there was a range of 0 to 85 days (median=14 days) in the interval between the quarterly screening questionnaire in which symptoms were reported and the examination where TMD caseclassification was determined.

\section{Quantitative Sensory Testing results}

Based on a univariate analysis, a subset of QST measures showed nominally significant $(\mathrm{P}<0.05)$ associations with TMD incidence. Pressure pain thresholds at cranial sites showed site-adjusted hazard ratios that ranged from $1.15(95 \% \mathrm{CI}=1.00-1.30)$ to $1.20(95 \% \mathrm{CI}=$ $1.05-1.37$ ), signifying relative increases of $15 \%$ to $20 \%$ in TMD incidence associated with an increase of one standard deviation in this measure of pain sensitivity (Table 1). Hazard ratios remained virtually identical after adjustment for demographic characteristics and after imputation for subjects who were not examined as intended. Two measures of mechanical cutaneous pain - overall ratings of 10 stimuli and 30s aftersensation ratings with the $512 \mathrm{mN}$ probe - were also nominally significant predictors of TMD incidence. The imputed and fully adjusted hazard ratios were 1.13 for overall ratings of 10 stimuli, and 1.16 for aftersensation pain ratings. Other responses to mechanical stimuli had hazard ratio 95\% CIs that crossed the value of 1.00, and were thus considered statistically non-significant (Table 1).

Among the heat pain measures, nine variables demonstrated significant site- and demographic-adjusted hazard ratios when imputed data were included in the analysis: 1-3) ratings of the series of ten heat stimuli (area under the curve) for all three temperatures; 4-6) maximum pain rating among the ten stimuli for all three temperatures; 7) aftersensation pain rating 15 seconds following a train of $48^{\circ} \mathrm{C}$ stimuli ; 8) heat pain temporal summation at $50^{\circ} \mathrm{C}$, based on the change of ratings between the first pulse and the highest rated pulse in the series; and 9) heat pain temporal summation at $50^{\circ} \mathrm{C}$, based on the slope derived from the ratings of the first three heat pulses (Table 2). Hazard ratios for these variables ranged from $1.12(95 \% \mathrm{CI}=1.00-1.26)$ to $1.24(95 \% \mathrm{CI}=1.06-1.44)$, signifying relative increases of $12 \%$ to $24 \%$ in TMD incidence associated with an increase of one standard deviation of the respective measure (Table 2).

Components derived from a PCA analysis of QST variables ${ }^{7}$ were also evaluated for associations with TMD incidence (Table 3). When assessed individually, none of the five factors produced significant hazard ratios. Multivariable analysis of these components revealed a marginally significant hazard ratio of $1.14(95 \% \mathrm{CI}=1.00-1.31)$ for the component related to pressure pain thresholds on TMD incidence.

Hazard ratios for QST PCA components did not vary significantly among demographic groups (Supplementary Table 1). However, when pairs of QST components were evaluated for potential interactions, the effect of heat pain temporal summation varied significantly across three levels of heat pain ratings (Supplementary Table 2). Specifically, the hazard ratio for the heat pain temporal summation principal component was $1.54(95 \% \mathrm{CI}=1.21-$ 1.94) in people with the lowest tercile of the heat pain ratings principal component. In other terciles, the hazard ratio rounded to the null value of 1.0. The nature of the interaction is depicted in Figure 1 using rates from an equivalent Poisson regression model. The highest 
incidence rate was seen among subjects in the lowest tercile of the heat pain rating component who had above average (+1 SD) temporal summation component scores. In comparison, the rate was less than half among subjects within that same tercile who had below average ( $-1 \mathrm{SD})$ temporal summation component scores. In other terciles of the heat pain ratings component, temporal summation component scores were not related to incidence rates (Figure 1).

This same pattern was observed in stratified analysis of individual thermal measures. Specifically, when analysis was restricted to those subjects who gave a rating between 0-20 for the first heat pain stimulus in a series, there were statistically significant hazard ratios for heat pain temporal summation for both $48^{\circ} \mathrm{C}$ and $50^{\circ} \mathrm{C}$ stimuli. In contrast, when the first heat pain rating was above 20 , hazard ratios based on temporal summation values were not statistically significant (Table 4).

The random forest model provided numeric and graphic results indicating the association of any single QST variable with TMD incidence, independent of the influence of other QST and demographic variables. In general, the QST variables showed weak or no association with TMD incidence, similar to the results of the univariate analysis described above. However, the graphic results provided for an evaluation of the extent of linear and nonlinear effects, the latter of which was not obtainable from the previous analyses. Within the mechanical domains, PPT for the TMJ and masseter muscle sites (Fig. 2a,b) showed a similar pattern, in that below a certain threshold level, PPTs had a monotonic relationship to TMD incidence (i.e., decreasing thresholds becoming more likely to indicate incident TMD cases), while above that level, there was relatively low incidence, which did not vary according to PPT value. The PPT for the epicondyle site (Fig 2c) showed a weak trend of greater TMD incidence with lower thresholds, but the confidence error range indicates a non-significant effect overall. The univariate analysis for epicondyle PPT also failed to show a significant hazard ratio (Table 1). Considering the mechanical cutaneous pain measures, threshold showed a similar profile as epicondyle PPT (Fig. 2d), and was also non-significant in the univariate analysis (Table 1). Both the mechanical pain temporal summation (Fig. 2e) and aftersensation (Fig. 2f) associated with the most intense cutaneous stimulus demonstrated a largely linear relationship with TMD incidence. Among the three heat pain measures depicted, each shows a different pattern, including a largely linear function ( $2 \mathrm{~h}$ ), and two different non-linear patterns $(2 \mathrm{~g}, \mathrm{i})$.

\section{Autonomic results}

Among the autonomic measures, only ECG-derived heart rate, which was determined on a beat-by-beat basis during the 20 minute rest period, showed a nominally significant hazard ratio (hazard ratio $=1.01, \mathrm{p}=0.023$; Supplementary Table 3 ), with higher resting heat rate associated with a greater incidence of TMD. When considering analysis of hazard ratios based on site- and demographically-adjusted data, and including imputed estimates, none were statistically significant for autonomic responses to orthostatic challenge (Supplemental Table 3), nor for the Stroop procedures (Supplementary Table 4). Three measures within the Stroop- Color protocol had marginal statistical significance based on unimputed data analysis (Supplementary Table 4). These results were considered spurious, given both the marginal level of significance, and the lack of any apparent link among these three measures.

Components derived from a PCA analysis of autonomic variables ${ }^{18}$ were also evaluated in terms of hazard ratios for TMD onset (Supplementary Table 5). None of the five components produced a significant hazard ratio, based on either univariate or multivariable analyses. 
Finally, an analysis of the influence of demographic factors (age, gender, and race/ethnicity) failed to show any significant effects upon hazard ratios for any of the autonomic PCA components (Supplementary Table 6).

\section{Discussion}

In this prospective study of first-onset TMD, the following key findings emerged:

1. Some, but not all measures of pain sensitivity assessed at study entry were associated with increased risk of developing TMD. Those measures associated with increased TMD incidence were: a) lower pressure pain thresholds measured at cranial sites, b) greater pain ratings for a series of either mechanical or heat stimuli, c) greater maximum pain ratings of heat stimuli, d) greater temporal summation of heat pain at $50^{\circ} \mathrm{C}$, and e) greater aftersensation ratings associated with either mechanical cutaneous or heat pain stimuli.

2. When individual QST measures were subjected to principal components analysis, none of the five derived components was a significant univariate predictor of TMD incidence, either for the overall cohort or in demographic subgroups. However, there was evidence of an interaction between the two principal components assessing heat pain responses: greater temporal summation of heat pain was associated with increased incidence of TMD among people with relatively low ratings of single-thermal stimuli, but not for people who had moderateor highratings of single-thermal stimuli.

3. Multivariable random forest models suggested that the relationship between QST variables and TMD incidence can be linear or non-linear, depending upon the specific pain sensitivity measure.

4. In contrast to the QST results, measures of autonomic function at study entry were largely not associated with incidence of first-onset TMD.

\section{QST measures as predictors of TMD incidence}

Several studies, ${ }^{7,16,17,23}$ including the OPPERA baseline case-control study, ${ }^{5}$, have reported that people with chronic TMD show enhanced sensitivity to experimental pain, even at nonsymptomatic body sites. However, those studies do not enable assessment of the causal relationship between pain sensitivity and the clinical pain. It has been proposed that a more "pain sensitive" individual is more susceptible to developing a clinical pain condition, considering that a lesser degree of provocation could lead to such a condition ${ }^{4}$. Indeed, one prospective TMD study showed that greater experimental pain sensitivity was associated with a higher TMD incidence rate ${ }^{25}$. Alternatively, development of a chronic pain condition could alter a person's nociceptive processing system, leading to an amplified representation of nociceptive signals within the CNS, frequently referred to as central sensitization ${ }^{29}$. The results of this study, along with those from previous studies evaluating chronic TMD cases, suggest both processes occur.

Fourteen of the 39 QST variables evaluated in this study showed statistically significant associations with TMD incidence. This was true for variables measured at cranial sites that eventually became symptomatic, as well as those measured at other body sites. One may expect that PPTs derived from the cranial sites were most likely to show significant hazard ratios, given that palpation pain from these same sites are part of the diagnostic criteria for TMD. Indeed this was found to be true, although several other pain measures derived from the forearm also provided significant hazard ratios. These observations support the theory that higher pre-morbid pain sensitivity contributes to risk of developing clinical pain, even when pain sensitivity is assessed beyond the site of clinical pain. Another prospective study 
evaluating predictors of factory work-related musculoskeletal pain also found that premorbid pressure pain sensitivity was significantly greater for individuals who developed such pain conditions versus those in the same environment who did not ${ }^{13}$. Also in line with the current study, Madeleine et al. found such significant differences only for a subset of experimental pain measures ${ }^{13}$. Thus, enhanced pre-morbid pain sensitivity appears to be somewhat selective, rather than global. Yet, based on the current study's results, the selectivity is not strictly based on anatomic location, stimulus modality, or specific types of pain measures.

Those QST variables showing statistically significant associations with TMD incidence showed marginal effect sizes, with hazard ratios ranging from 1.12 to 1.24. Only four of these hazard ratios were statistically significant at the $p<0.01$ level, and none were significant at the Bonferroni-adjusted criteria of $p<0.00128$. These results contrast dramatically with the OPPERA baseline case-control study of chronic TMD, which used these same pain sensitivity measures ${ }^{7}$. For example, nearly all QST measures had highly significant associations, as signified by P-values less than 0.001 . For each measure of pain sensitivity, hazard ratios in this prospective cohort study were uniformly lower than corresponding odds ratios in the casecontrol study, although hazard ratios and odds ratios cannot be directly compared. Nonetheless, these distinct and sizable differences in strength of association of pain sensitivity with chronic TMD versus first-onset TMD support the theory that the induction of chronic pain further enhances a person's overall pain sensitivity. Furthermore, these finding suggest the possibility that the biological mechanisms contributing to the enhanced pain sensitivity with chronicity may be the same critical processes that contribute, at least in part, to the transition from acute to chronic TMD.

None of the QST PCA components individually revealed a statistically significant hazard ratio. This is consistent with the observation that only a minority of QST measures showed statistically significant hazard ratios in univariate analyses, and these significant measures were not concentrated within a single PCA component. However, those mechanical cutaneous and heat pain measures that did produce significant hazard ratios could be characterized as involving ratings of 1) multiply applied stimuli, and 2) the more intense stimuli.

Unexpectedly, an interaction between two PCA components revealed a significant hazard ratio: for those cases in which ratings of heat pain intensity were lower, greater temporal summation of heat pain was predictive of TMD incidence. Specifically, for the lowest tercile of the PCA component related to heat pain sensitivity, the PCA component related to temporal summation produced a hazard ratio of 1.6 - the highest seen for any QST measure. This result does not correspond with any previously described model. Enhanced heat pain temporal summation was not generally found for chronic TMD cases in our previous report ${ }^{7}$. However, a more detailed analysis of those results demonstrate that heat pain temporal summation can distinguish TMD cases from controls for instances in which initial stimuli are reported as only mildly painful (Rothwell, unpublished, 2012). These two congruent sets of observations show that while all groups demonstrate some degree of heat pain temporal summation, differences between healthy controls and either incident TMD cases to be, or chronic TMD cases are only demonstrable when an initial stimulus is rated as weakly painful. In that situation, a large degree of temporal summation is possible. When initial stimuli are rated as more strongly painful, the range of possible values for temporal summation is less, and is more similar between groups. This may be due to a ceiling effect in heat pain ratings per se (e.g., reporting "100" routinely), although analysis of chronic TMD case-control data would suggest otherwise (Rothwell, unpublished, 2012). Instead, it may reflect a greater ability for healthy controls to restrict the degree of temporal summation 
to a certain range, which is only evident when initial pain intensity is low, and a large range of temporal summation is possible. More exploration of this topic is clearly warranted.

Another factor that demands consideration is that only some of the incident TMD cases in this study are likely to become chronic TMD cases. Based on other studies, ${ }^{5,20}$, one would predict that less than half of the incident cases will become chronic TMD cases. If premorbid experimental pain sensitivity is related only to the development of chronic TMD, then this relationship could be obscured in the current analysis, as we cannot differentiate between those incident cases who will become chronic versus those who will resolve, and thus only be considered as acute cases. If the analyses were limited to those who develop chronic TMD, one would predict that a closer relationship between the incident hazard ratios and case-control odds ratios would emerge. Furthermore, as noted in a companion paper ${ }^{24}$, the annual incidence of $3.5 \%$ observed here exceeds the rate reported in most other prospective cohort studies of TMD, although it is similar to the rate found in one prospective cohort study of young women. ${ }^{21}$

\section{Autonomic measures as predictors of TMD incidence}

One of the autonomic measures produced a marginally significant hazard ratio for TMD incidence: heart rate during rest. This measure also produced a significant odds ratio of 1.3 for chronic TMD in the OPPERA case-control study ${ }^{18}$. The observation that increased heart rate is associated with increased incidence of TMD is consistent with the hypothesis that augmented sympathetic activity, which results from a central impairment in baroreceptor function and is reflected by an increase in resting heart rate, contributes to the onset and chronicity of musculoskeletal pain conditions such as TMD and fibromyalgia. ${ }^{14}$

Furthermore, a systematic increase in the incidence rate was observed from the lowest to the highest tercile of resting heart rate. Thus, it may be that individuals in the highest tercile are more likely to develop chronic TMD compared to individuals in the lower two tertiles ${ }^{11,27}$. It should also be appreciated that the current level of analyses does not fully account for the potential importance of autonomic variables in predicting the onset of TMD. More sophisticated multivariable analyses that incorporate variables across several domains (e.g. clinical, psychosocial, and genetic) are needed prior to concluding that measures of autonomic function fail to predict and to contribute to the incidence of TMD.

\section{Conclusions}

This study's findings should be interpreted in light of a few limitations. First, multiple analyses were performed on a large number of variables, yet we presented and interpreted the results individually, making no formal adjustments for multiple testing. Accordingly, hazard ratio statistics are presented in as full a fashion as possible, for both univariate and multivariable analyses, so readers can review and interpret these results. Second, while we examined some of the potential interactions among factors (e.g. demographic measures and PCA components), many other possible interactions were not tested (e.g. among individual QST measures) due to the exceedingly large number of statistical tests this would require. Third, the current analyses are restricted to the QST and autonomic data and do not examine potentially important associations and interactions between these two sets of data, or among other phenotypic measures. However, cross-domain analyses are presented elsewhere in this volume, which explore TMD incidence risk in a fuller context ${ }^{24}$. Finally, the current analyses examine only pain sensitivity and autonomic risk factors for first-onset TMD, and do not speak to predictors of transition from acute to chronic TMD, which is a question of high clinical and mechanistic significance. Such analyses are planned for future manuscripts from this project. 
These limitations notwithstanding, the current findings reveal that enhanced pain sensitivity is a risk factor for first onset TMD, although demonstrable in only a subset of pain measures. In general, QST-derived risk factors predicted TMD incidence similarly across demographic categories. In contrast, cardiovascular autonomic measures provided little evidence as risk factors for TMD incidence. Future analyses will examine associations of these variables with transition from acute to chronic pain, and changes in both pain sensitivity and autonomic function that accompany onset of TMD will also be explored.

\section{Supplementary Material}

Refer to Web version on PubMed Central for supplementary material.

\section{Acknowledgments}

The authors would like to thank the OPPERA research staff at each of four study sites and the data coordination center for their invaluable contributions to this work. In addition, we express our gratitude to the participants who have devoted time and effort in support of this research.

\section{References}

1. Adams J. A computer experiment to evaluate regression strategies. Proceedings of the American Statistical Association Section on Statistical Computing. 1991

2. Bair E, Brownstein N, Ohrbach R, Greenspan J, Dubner R, Fillingim R, Maixner W, Smith S, Diatchenko L, Gonzalez Y, Gordon S, Lim P-F, Ribeiro-Dasilva M, Dampier D, Knott C, Slade GD. Study protocol, sample characteristics and loss-to-follow-up: the OPPERA prospective cohort study. (THIS ISSUE).

3. Breiman L. Random forests. Machine Learning. 2001; 45:5-32.

4. Diatchenko L, Nackley AG, Slade GD, Fillingim RB, Maixner W. Idiopathic pain disorders Pathways of vulnerability. Pain. 2006; 123:226-30. [PubMed: 16777329]

5. Garofalo JP, Gatchel RJ, Wesley AL, Ellis E III. Predicting chronicity in acute temporomandibular joint disorders using the research diagnostic criteria. J Am Dent Assoc. 1998; 129:438-47. [PubMed: 9573694]

6. Greenland S. Invited commentary: variable selection versus shrinkage in the control of multiple confounders. Am J Epidemiol. 2008; 167:523-9. [PubMed: 18227100]

7. Greenspan JD, Slade GD, Bair E, Dubner R, Fillingim RB, Ohrbach R, Knott C, Mulkey F, Rothwell R, Maixner W. Pain sensitivity risk factors for chronic TMD: descriptive data and empirically identified domains from the OPPERA case control study. J Pain. 2011; 12:T61-T74. [PubMed: 22074753]

8. Hastie, T.; Tibshirani, R.; Friedman, J. The Elements of Statistical Learning: Data Mining, Inference, and Prediction. New York: Springer; 2009.

9. Hu YJ, Ku TH, Jan RH, Wang K, Tseng YC, Yang SF. Decision tree-based learning to predict patient controlled analgesia consumption and readjustment. BMC Med Inform Decis Mak. 2012; 12:131. [PubMed: 23148492]

10. Ishwaran H, Kogalur UB, Blackstone EH, Lauer MS. Random survival forests. Annals of Applied Statistics. 2008; 2:841-60.

11. Light KC, Bragdon EE, Grewen KM, Brownley KA, Girdler SS, Maixner W. Adrenergic dysregulation and pain with and without acute beta-blockade in women with fibromyalgia and temporomandibular disorder. J Pain. 2009; 10:542-52. [PubMed: 19411061]

12. Loader, C. Local Regression and Likelihood. New York: Springer; 1999.

13. Madeleine P, Lundager B, Voigt M, Arendt-Nielsen L. The effects of neck-shoulder pain development on sensory-motor interactions among female workers in the poultry and fish industries. A prospective study. Int Arch Occup Environ Health. 2003; 76:39-49. [PubMed: 12592581] 
14. Maixner, W. Biopsychosocial and genetic risk factors for temporomandibular joint disorders and related conditions. In: Graven-Nielsen, T.; Arendt-Nielsen, L.; Mense, S., editors. Fundamentals of Musculoskeletal Pain. IASP Press; Seattle: 2008. p. 263-79.

15. Maixner, W. Temporomandibular Joint Disorders. In: Mayer, EA.; Bushnell, MC., editors. Functional Pain Syndromes: Presentation and Pathophysiology. IASP Press; Seattle: 2009. p. 55-70.

16. Maixner W, Fillingim R, Booker D, Sigurdsson A. Sensitivity of patients with painful temporomandibular disorders to experimentally evoked pain. Pain. 1995; 63:341-51. [PubMed: 8719535]

17. Maixner W, Fillingim R, Sigurdsson A, Kincaid S, Silva S. Sensitivity of patients with painful temporomandibular disorders to experimentally evoked pain: evidence for altered temporal summation of pain. Pain. 1998; 76:71-81. [PubMed: 9696460]

18. Maixner W, Greenspan JD, Dubner R, Bair E, Mulkey F, Miller V, Knott C, Slade GD, Ohrbach R, Diatchenko L, Fillingim RB. Potential autonomic risk factors for chronic TMD: descriptive data and empirically identified domains from the OPPERA case-control study. J Pain. 2011; 12:T75T91. [PubMed: 22074754]

19. Ohrbach R, Bair E, Fillingim RB, Gonzalez Y, Gordon SM, Lim P-F, Ribeiro-Dasilva M, Diatchenko L, Dubner R, Greenspan JD, Knott C, Maixner M. Clinical orofacial characteristics associated with risk of first-onset TMD: the OPPERA prospective cohort study. (THIS ISSUE).

20. Ohrbach R, Dworkin SF. Five-year outcomes in TMD: relationship of changes in pain to changes in physical and psychological variables. Pain. 1998; 74:315-26. [PubMed: 9520246]

21. Plesh O, Gansky SA, Curtis DA. Chronic pain in a biracial cohort of young women. The Open Pain Journal. 2012; 5:24-31. [PubMed: 24489616]

22. Riddle DL, Kong X, Jiranek WA. Two-year incidence and predictors of future knee arthroplasty in persons with symptomatic knee osteoarthritis: preliminary analysis of longitudinal data from the osteoarthritis initiative. Knee. 2009; 16:494-500. [PubMed: 19419874]

23. Sarlani E, Grace EG, Reynolds MA, Greenspan JD. Evidence for up-regulated central nociceptive processing in patients with masticatory myofascial pain. J Orofac Pain. 2004; 18:41-55. [PubMed: 15029872]

24. Slade GD, Bair E, Greenspan J, Dubner R, Fillingim R, Diatchenko L, Maixner W, Knott C, Ohrbach R. Signs and symptoms of first-onset TMD and socio-demographic predictors of its development: the OPPERA prospective cohort study. (THIS ISSUE).

26. Svensson P, List T, Hector G. Analysis of stimulus-evoked pain in patients with myofascial temporomandibular pain disorders. Pain. 2001; 92:399-409. [PubMed: 11376913]

27. Tchivileva IE, Lim PF, Smith SB, Slade GD, Diatchenko L, McLean SA, Maixner W. Effect of catechol-O-methyltransferase polymorphism on response to propranolol therapy in chronic musculoskeletal pain: a randomized, double-blind, placebo-controlled, crossover pilot study. Pharmacogenet Genomics. 2010; 20:239-48. [PubMed: 20216107]

28. Wolfe F, Clauw DJ, Fitzcharles MA, Goldenberg DL, Katz RS, Mease P, Russell AS, Russell IJ, Winfield JB, Yunus MB. The American College of Rheumatology preliminary diagnostic criteria for fibromyalgia and measurement of symptom severity. Arthritis Care Res (Hoboken ). 2010; 62:600-10. [PubMed: 20461783]

29. Woolf CJ. Central sensitization: Implications for the diagnosis and treatment of pain. Pain. 2011; 152:S2-S15. [PubMed: 20961685] 


\section{Perspective}

Our previous case-control studies showed that associations with both pain sensitivity and cardiac autonomic function are profound in chronic TMD cases. Here we show that some measures of enhanced pain sensitivity contribute modestly to the risk of developing TMD, while autonomic dysregulation appears to confer little or no risk for TMD incidence. 

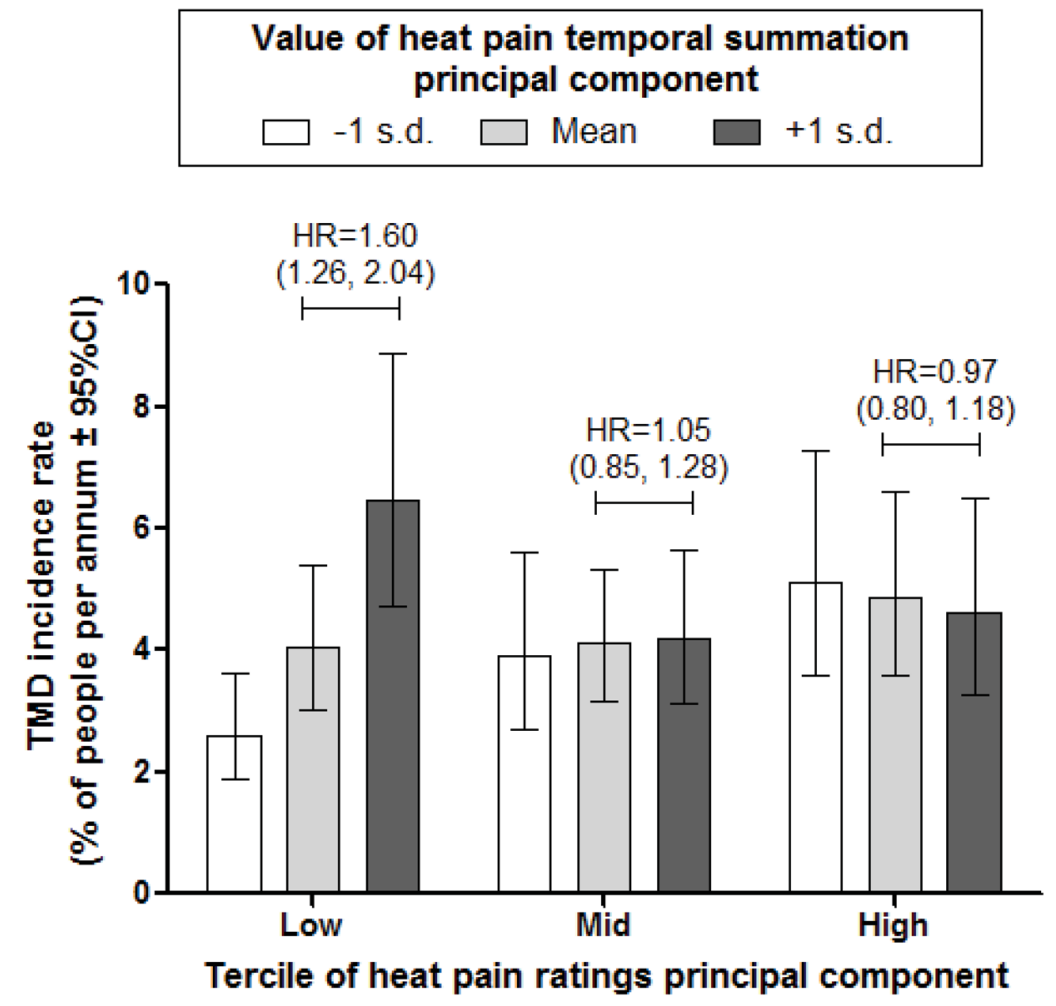

Figure 1.

Imputed TMD incidence rates and hazard ratios for heat pain temporal summation stratified to tercile of heat pain ratings. Incidence rates of first-onset TMD were computed using multivariable Poisson regression models with multiple imputation to account for subjects who were not examined as intended. Covariates were study site (categorical variable, 4 levels), age (in years, with rates estimated for three selected age groups: 20, 30 and 40 years), race/ethnicity (5 categories - rates not shown for "other/unknown" race category) and lifetime US residence ( 2 categories), heat pain rating principal component, heat pain temporal summation principal component, and the interaction of the two principal components. Hazard ratios (HR) represent effect of 1 S.D. increase in the degree of temporal summation on TMD incidence. They were calculated using multivariable Cox regression models with the same covariates described for the Poisson models. 

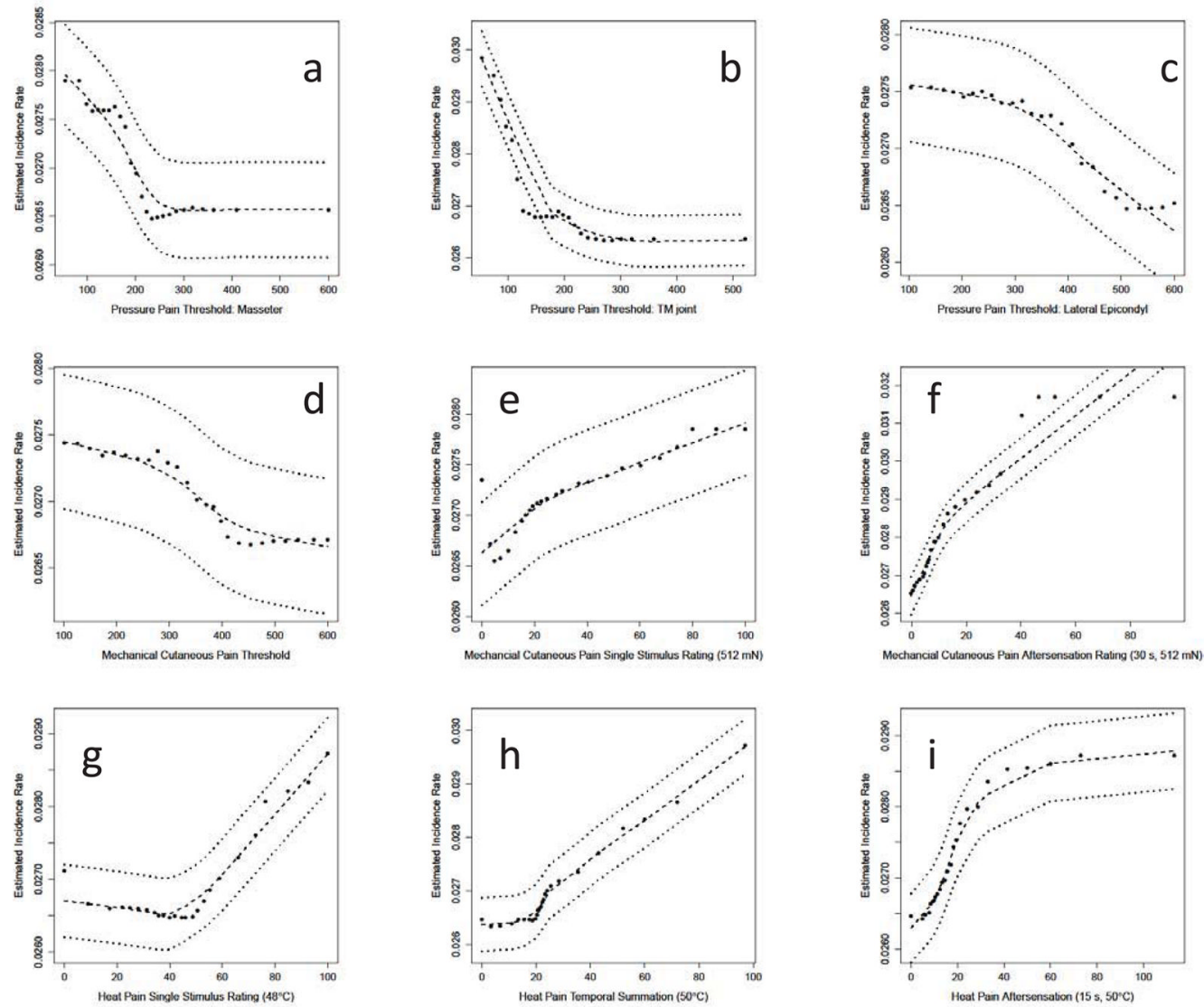

Figure 2.

Partial Dependence Plots for several of the QST measures. The plots depict the estimated TMD incidence rate that would be observed at several values of the variable after averaging over the values of all other variables in the model. TMD incidence rates, expressed as cases per 100-person-years, were generated from random forest models that predicted TMD onset using study site, demographic variables, and QST variables presented in Table 1. Predicted values (O) are plotted together with LOESS-smoothed estimates (- - ) and their 95\% confidence intervals $\left({ }^{\cdots \cdots}\right)$. 


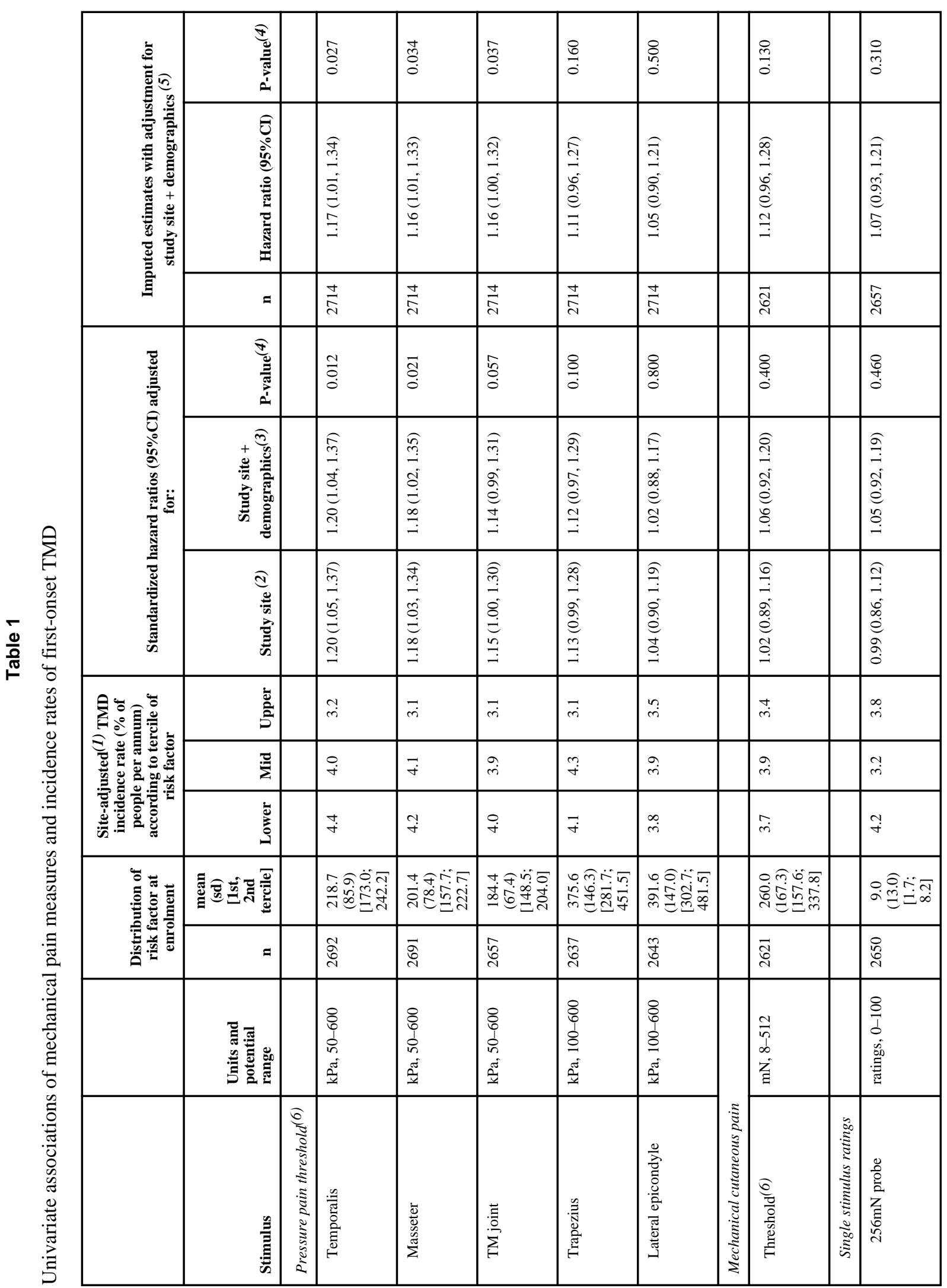




\begin{tabular}{|c|c|c|c|c|c|c|c|c|c|c|c|c|}
\hline \multirow{3}{*}{ 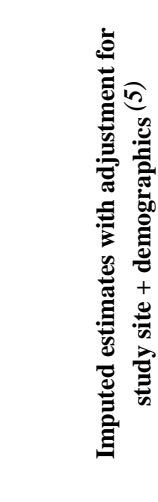 } & 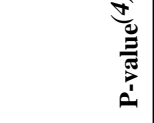 & ôे & & 导 & $\begin{array}{l}\infty \\
0 \\
0 \\
0\end{array}$ & & $\frac{8}{0}$ & $\frac{2}{0}$ & $\vec{\circ}$ & है & & $\begin{array}{l}\mathscr{D} \\
\infty \\
\infty \\
0\end{array}$ \\
\hline & 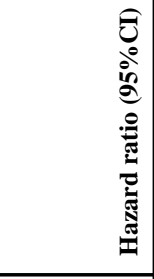 & 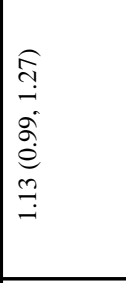 & & 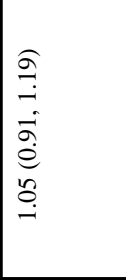 & 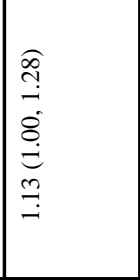 & & 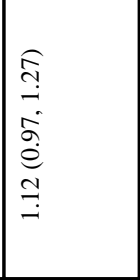 & 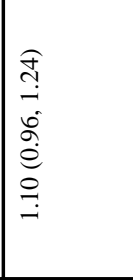 & 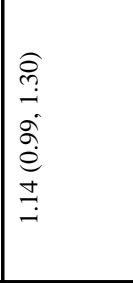 & 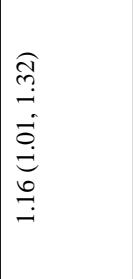 & & 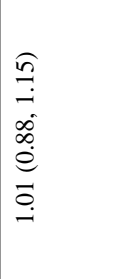 \\
\hline & $=$ & $\hat{\tilde{c}}$ & & $\hat{\tilde{\sigma}}$ & 芯 & & 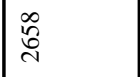 & $\begin{array}{l}\infty \\
\text { ڤ్రి } \\
\end{array}$ & $\begin{array}{l}\infty \\
\stackrel{్}{0} \\
\end{array}$ & 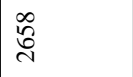 & & $\hat{\tilde{d}}$ \\
\hline \multirow{3}{*}{ 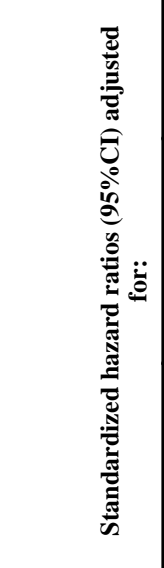 } & 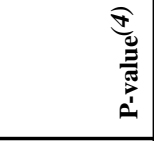 & ồ & & $\begin{array}{l}9 \\
\substack{9 \\
0 \\
0 \\
0}\end{array}$ & त्र్గి & & 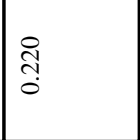 & $\frac{9}{0}$ & $\stackrel{0}{=}$ & $\stackrel{n}{\tilde{c}}$ & & : \\
\hline & 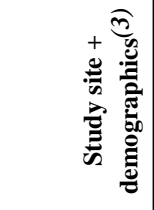 & 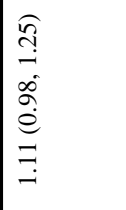 & & 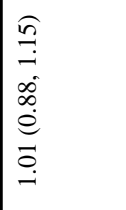 & 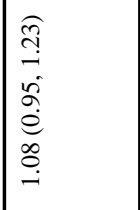 & & 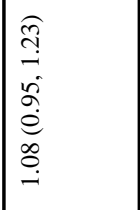 & 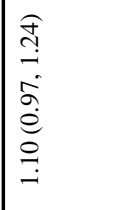 & 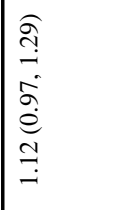 & 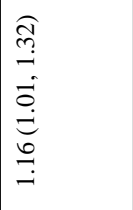 & & 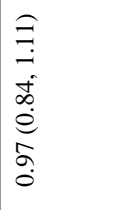 \\
\hline & 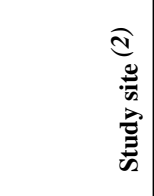 & 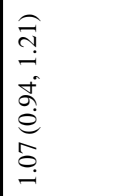 & & 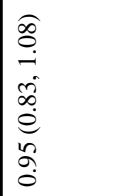 & 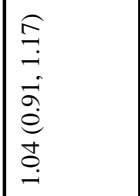 & & 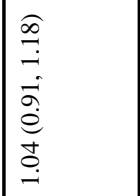 & 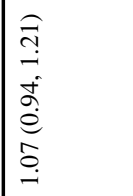 & 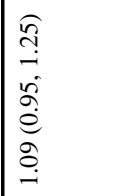 & 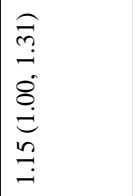 & & 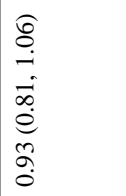 \\
\hline \multirow{3}{*}{ 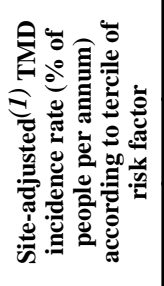 } & s.ّ. & $\vec{r}$ & & $\dot{m}$ & $\dot{\vec{r}}$ & & & . & . & . & & $\ddot{m}$ \\
\hline & $\bar{\Sigma}$ & $\stackrel{m}{m}$ & & $\stackrel{n}{m}$ & $\stackrel{n}{n}$ & & & . & . & . & & $\stackrel{\leftrightarrow}{\circ}$ \\
\hline & 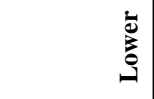 & $\stackrel{0}{\infty}$ & & $F$ & $\stackrel{\odot}{\circ}$ & & & . & . & . & & $\stackrel{\mathscr{F}}{\rightarrow}$ \\
\hline \multirow{3}{*}{ 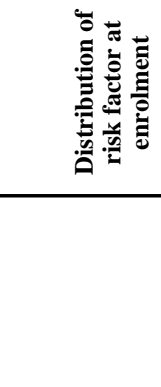 } & 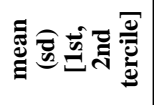 & 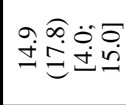 & & 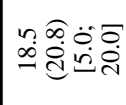 & 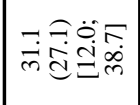 & & 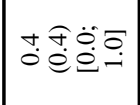 & 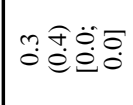 & 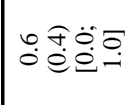 & 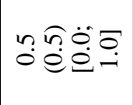 & & م \\
\hline & $=$ & $\begin{array}{l}\infty \\
\stackrel{\infty}{+} \\
\sim\end{array}$ & & 吕 & 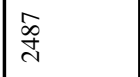 & & 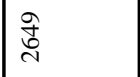 & 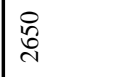 & 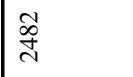 & 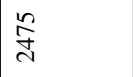 & & ?q \\
\hline & 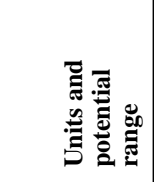 & 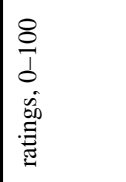 & \multirow{2}{*}{ 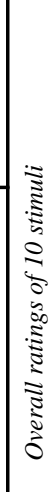 } & $\begin{array}{l}8 \\
0 \\
0 \\
0 \\
\text { s. } \\
\text { 离 } \\
0\end{array}$ & 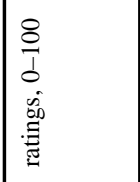 & & 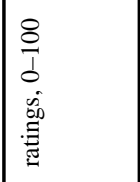 & 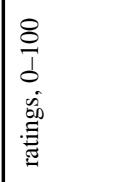 & 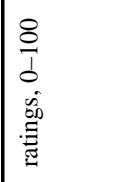 & 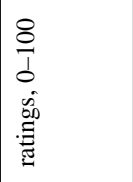 & & 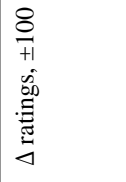 \\
\hline & 章 & 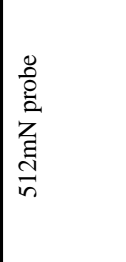 & & 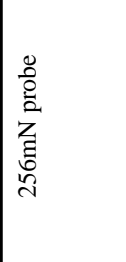 & 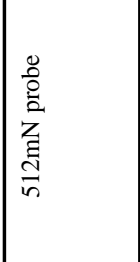 & 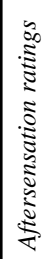 & 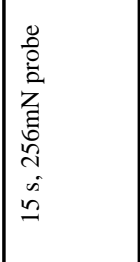 & 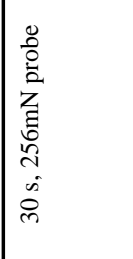 & 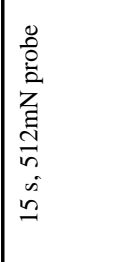 & 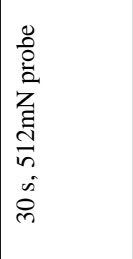 & 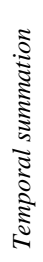 & 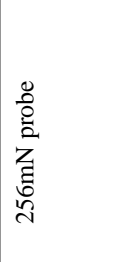 \\
\hline
\end{tabular}




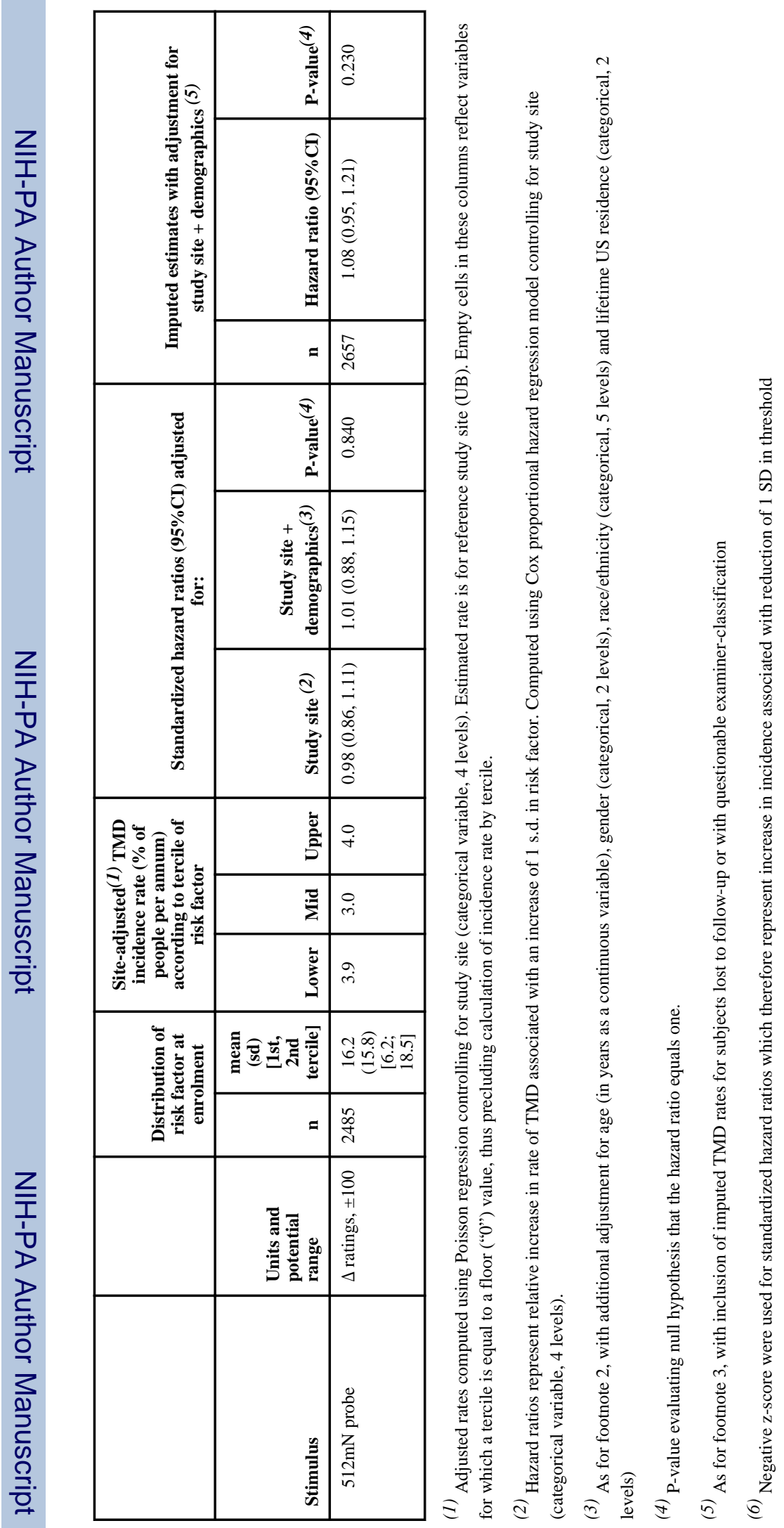

J Pain. Author manuscript; available in PMC 2014 December 01. 


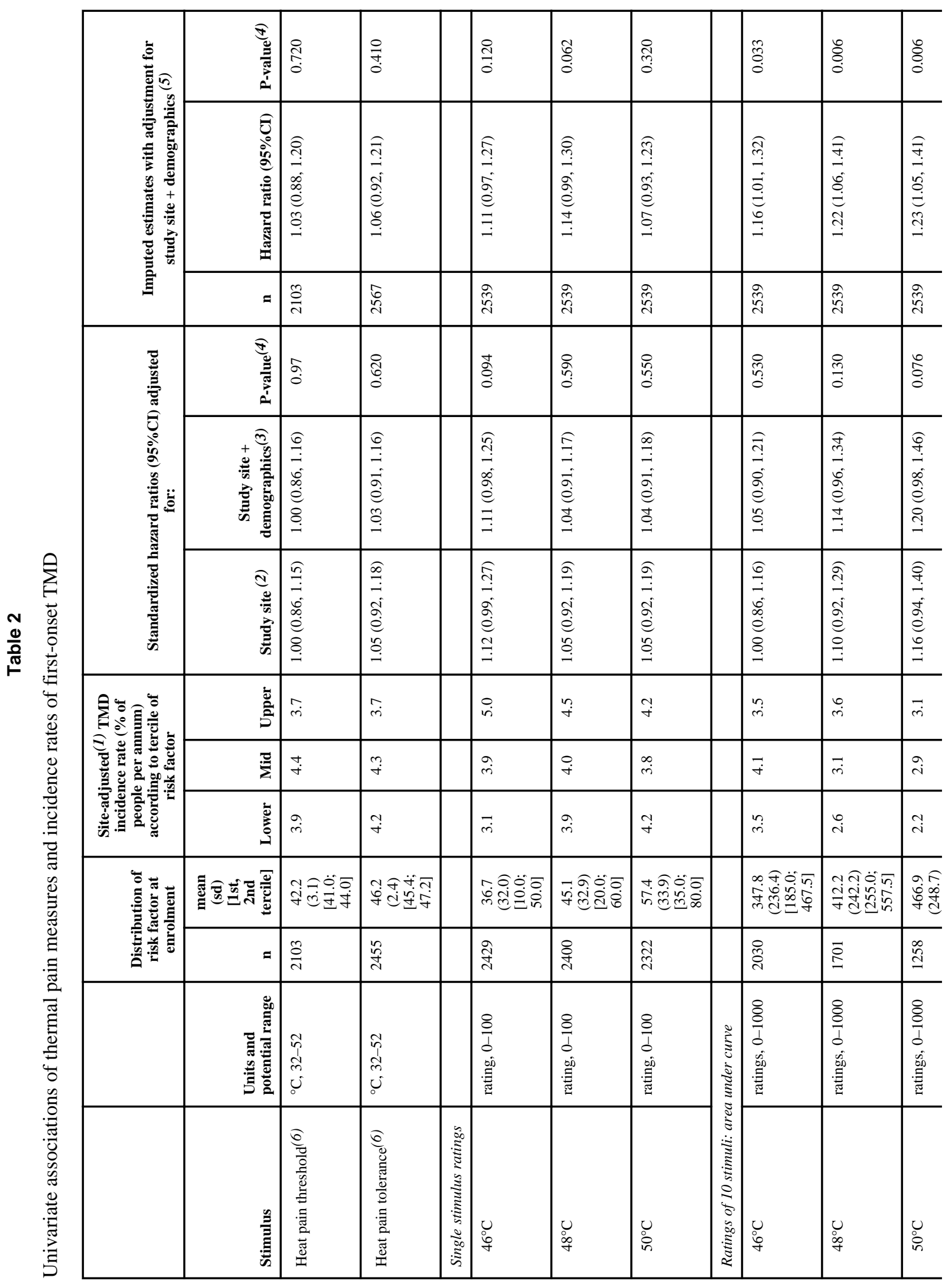

J Pain. Author manuscript; available in PMC 2014 December 01. 


\begin{tabular}{|c|c|c|c|c|c|c|c|c|c|c|c|c|}
\hline \multirow{3}{*}{ 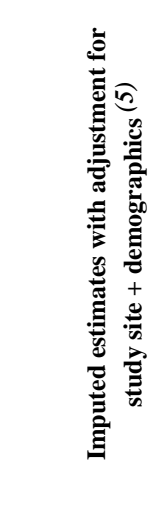 } & 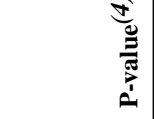 & & & है & $\stackrel{n}{0}$ & $\stackrel{n}{o}$ & & $\begin{array}{l}\text { ते } \\
\text { ?े }\end{array}$ & 奋 & 范 & $\frac{9}{0}$ & 官 \\
\hline & 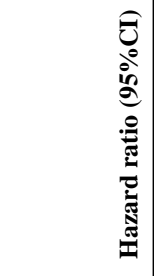 & & & 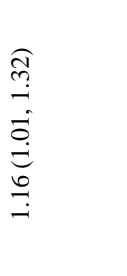 & 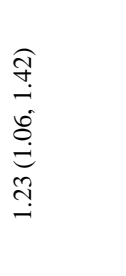 & 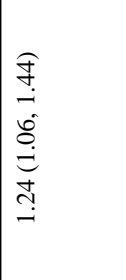 & & 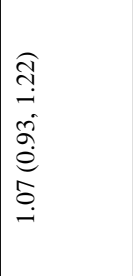 & 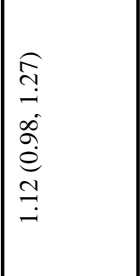 & 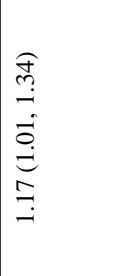 & 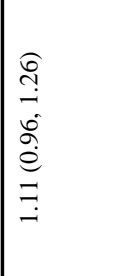 & 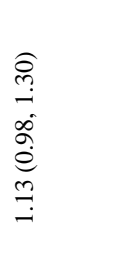 \\
\hline & $=$ & & & ते & हे & हुे & & 索 & 节 & \begin{tabular}{l}
+ \\
\multirow{n}{n}{} \\
ñ
\end{tabular} & 索 & 节 \\
\hline \multirow{3}{*}{ 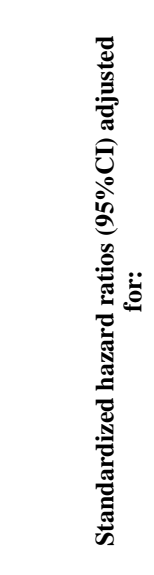 } & 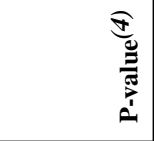 & & & oे & $\stackrel{t}{0}$ & oे. & & $\frac{8}{\circ}$ & $\begin{array}{l}0 \\
0 \\
0 \\
0 \\
0\end{array}$ & $\vec{\Xi}$ & $\begin{array}{l}\infty \\
\infty \\
0 \\
0 \\
0\end{array}$ & : \\
\hline & 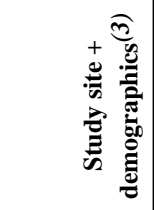 & & & 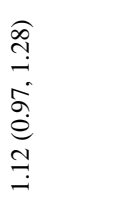 & 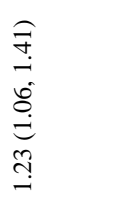 & 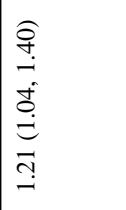 & & 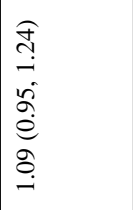 & 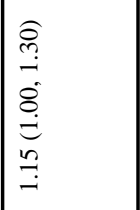 & 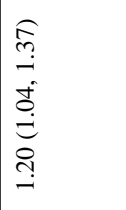 & 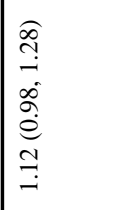 & 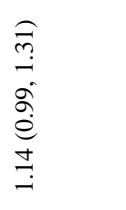 \\
\hline & 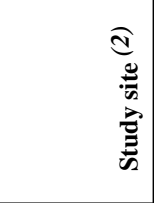 & & & 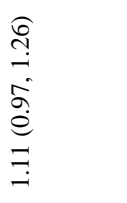 & 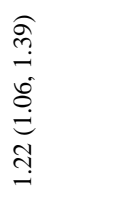 & 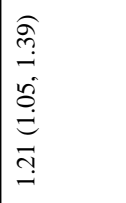 & & 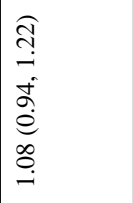 & 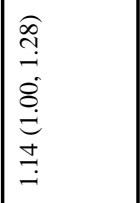 & 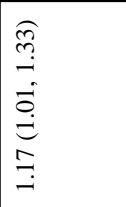 & 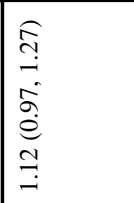 & 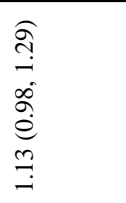 \\
\hline \multirow{3}{*}{ 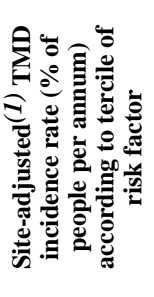 } & 产 & & & $\stackrel{\leftrightarrow}{+}$ & $\stackrel{\sim}{n}$ & . & & & & & . & r \\
\hline & $\bar{z}$ & & & $\vec{m}$ & $\vec{f}$ & . & & & & & & \\
\hline & 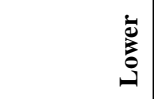 & & & $\stackrel{\infty}{\dot{m}}$ & $\ddot{n}$ & & & & & & & \\
\hline \multirow{4}{*}{ 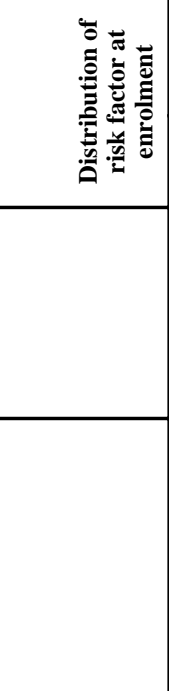 } & 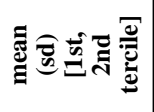 & 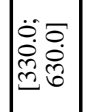 & & 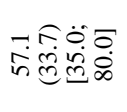 & 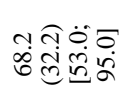 & 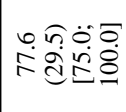 & & 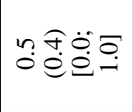 & 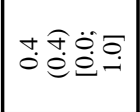 & 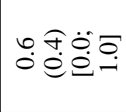 & 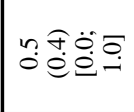 & 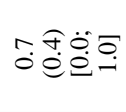 \\
\hline & $=$ & & & 范 & 今ે & ปิ & & 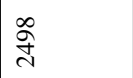 & \& & है & 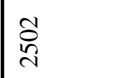 & $\stackrel{n}{o}$ \\
\hline & 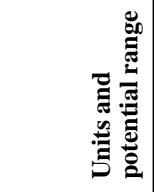 & & \multirow{2}{*}{ 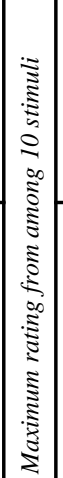 } & 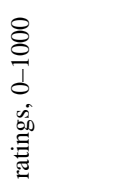 & 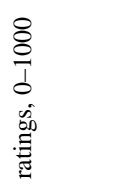 & 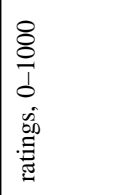 & & 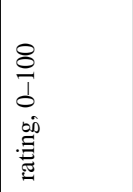 & 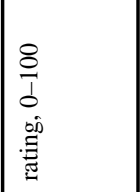 & \begin{tabular}{l}
8 \\
$\frac{1}{1}$ \\
oi \\
婄 \\
\hdashline
\end{tabular} & 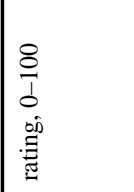 & 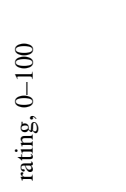 \\
\hline & 呈 & & & $\begin{array}{l}ن \\
\dot{q}\end{array}$ & $\begin{array}{l}0 \\
\stackrel{0}{+} \\
\stackrel{+}{+}\end{array}$ & : & 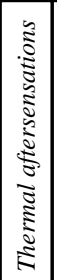 & $\begin{array}{l} \\
\\
0 \\
0 \\
0 \\
\vdots \\
i \\
n \\
n \\
n\end{array}$ & $\begin{array}{l}0 \\
0 \\
\dot{0} \\
\dot{0} \\
\dot{0} \\
0 \\
m\end{array}$ & $\begin{array}{l}0 \\
0 \\
\infty \\
\dot{0} \\
\dot{n} \\
n\end{array}$ & $\begin{array}{l}0 \\
0 \\
o \\
+ \\
\text { s. } \\
0 \\
0\end{array}$ & $\begin{array}{l}0 \\
0 \\
n \\
i \\
n \\
n\end{array}$ \\
\hline
\end{tabular}




\begin{tabular}{|c|c|c|c|c|c|c|c|c|c|c|}
\hline \multirow{3}{*}{ 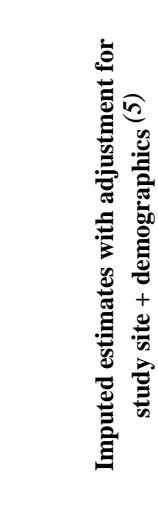 } & 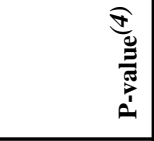 & $\stackrel{8}{0}$ & & $\frac{0}{m}$ & $\begin{array}{c}8 \\
\text { ֻ } \\
0\end{array}$ & ळे. & & in & $\stackrel{\infty}{0}$ & $\begin{array}{l}\text { J } \\
\stackrel{0}{0}\end{array}$ \\
\hline & 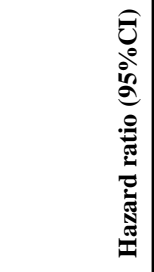 & 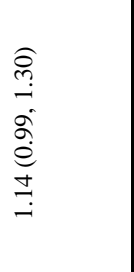 & & 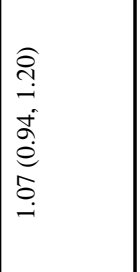 & 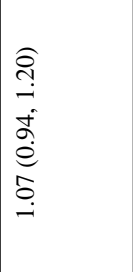 & 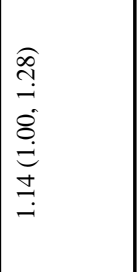 & & 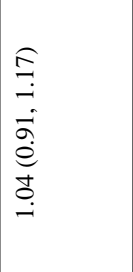 & 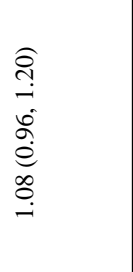 & 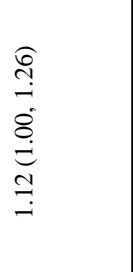 \\
\hline & $=$ & $\begin{array}{l}0 \\
0 \\
i\end{array}$ & & હે & $\begin{array}{l}\hat{\tilde{N}} \\
\text { הु) }\end{array}$ & $\begin{array}{l}\text { ले } \\
\text { ते }\end{array}$ & & 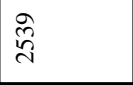 & हुે & त्रे \\
\hline \multirow{3}{*}{ 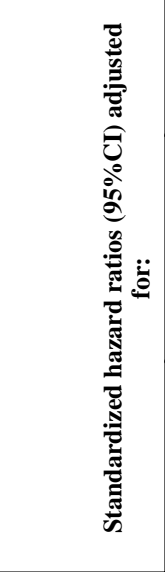 } & 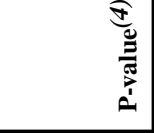 & 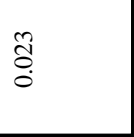 & & $\begin{array}{l}\infty \\
\stackrel{0}{\circ} \\
0\end{array}$ & $\stackrel{\substack{m \\
0}}{0}$ & $\stackrel{0}{0}$ & & $\begin{array}{l}0 \\
\substack{0 \\
0 \\
0}\end{array}$ & 昌 & 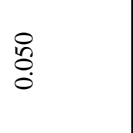 \\
\hline & 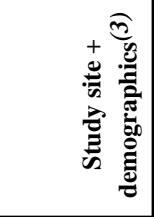 & 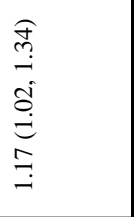 & & 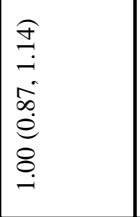 & 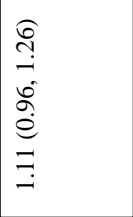 & 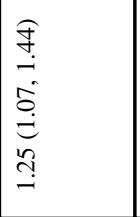 & & $\begin{array}{l}\hat{m} \\
\stackrel{0}{0} \\
0 \\
\infty \\
\stackrel{0}{0} \\
o \\
0 \\
0\end{array}$ & 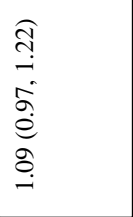 & 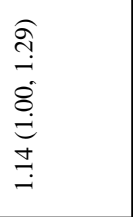 \\
\hline & 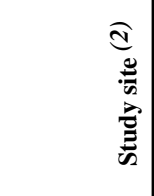 & 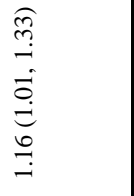 & & 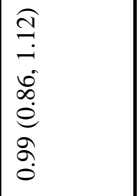 & 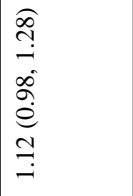 & 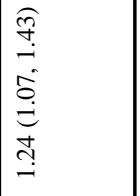 & & 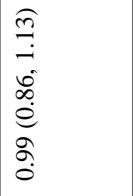 & 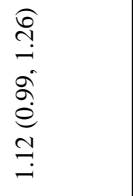 & 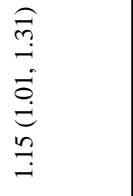 \\
\hline \multirow{3}{*}{ 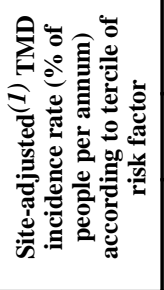 } & s. & . & & $\stackrel{\overrightarrow{+}}{\dot{+}}$ & $\bar{F}$ & $\stackrel{\sim}{+}$ & & $\begin{array}{l}\stackrel{\sim}{r} \\
\stackrel{+}{*}\end{array}$ & के & 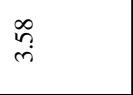 \\
\hline & $\bar{\Sigma}$ & . & & $\stackrel{n}{\underset{f}{*}}$ & $\begin{array}{l}\infty \\
\infty \\
\infty\end{array}$ & $\widehat{i}$ & & $\underset{c}{\forall}$ & $\stackrel{f}{\stackrel{f}{m}}$ & $\underset{\sim}{F}$ \\
\hline & 离 & . & & $\underset{\dot{m}}{8}$ & $\vec{m}$ & $\begin{array}{l}\infty \\
i \\
i\end{array}$ & & $\underset{f}{F}$ & $\stackrel{\partial}{\vec{r}}$ & $\underset{m}{\Delta}$ \\
\hline \multirow{3}{*}{ 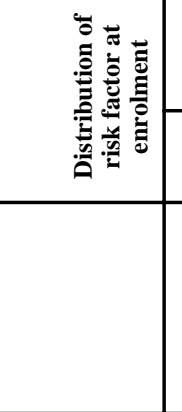 } & 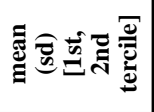 & ? & & 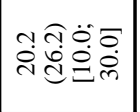 & 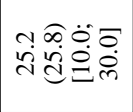 & 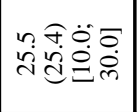 & & 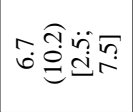 & 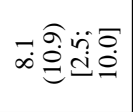 & 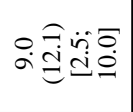 \\
\hline & $=$ & $\overrightarrow{\vec{j}}$ & & $\begin{array}{l}\text { ర్ల్ } \\
\text { ( }\end{array}$ & 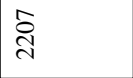 & $\stackrel{\widetilde{\Omega}}{\Omega}$ & \multirow{3}{*}{ 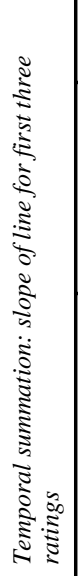 } & 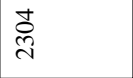 & $\overline{\vec{\lambda}}$ & సิ \\
\hline & 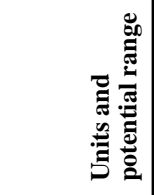 & 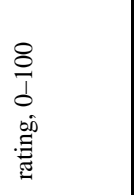 & \multirow{2}{*}{ 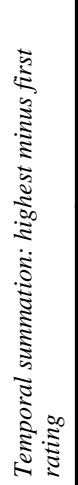 } & 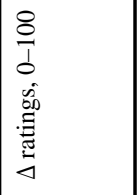 & 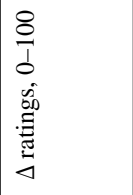 & 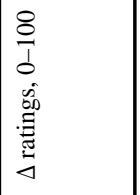 & & 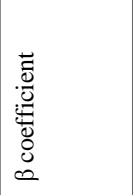 & 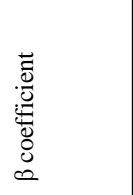 & 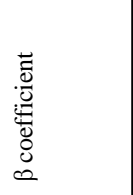 \\
\hline & 虽 & $\begin{array}{l}i n \\
i \\
i \\
i\end{array}$ & & \begin{tabular}{l}
0 \\
0 \\
$\vdots$ \\
\hdashline
\end{tabular} & 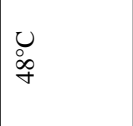 & $\begin{array}{l}0 \\
:\end{array}$ & & 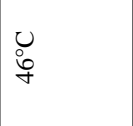 & 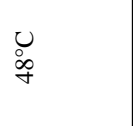 & $\begin{array}{l}0 \\
\text { Oे }\end{array}$ \\
\hline
\end{tabular}




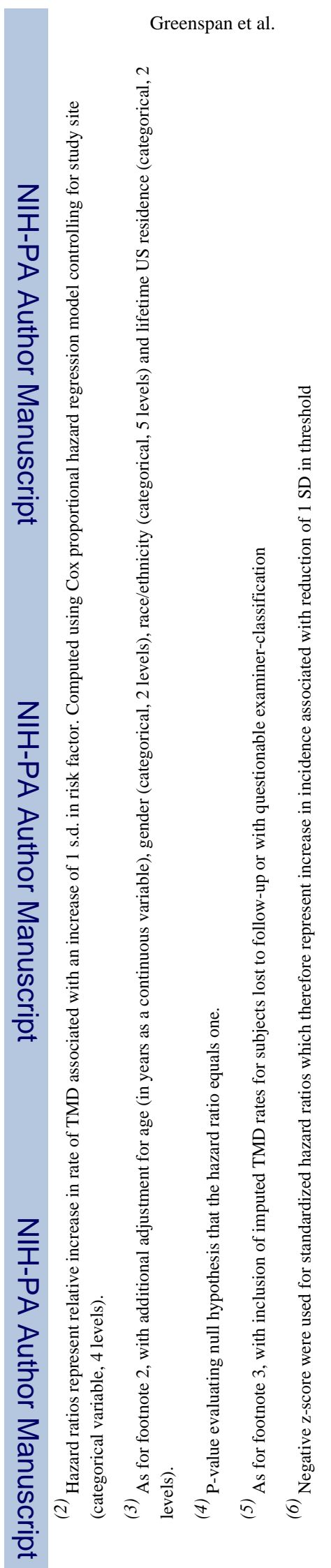

Page 21

J Pain. Author manuscript; available in PMC 2014 December 01. 


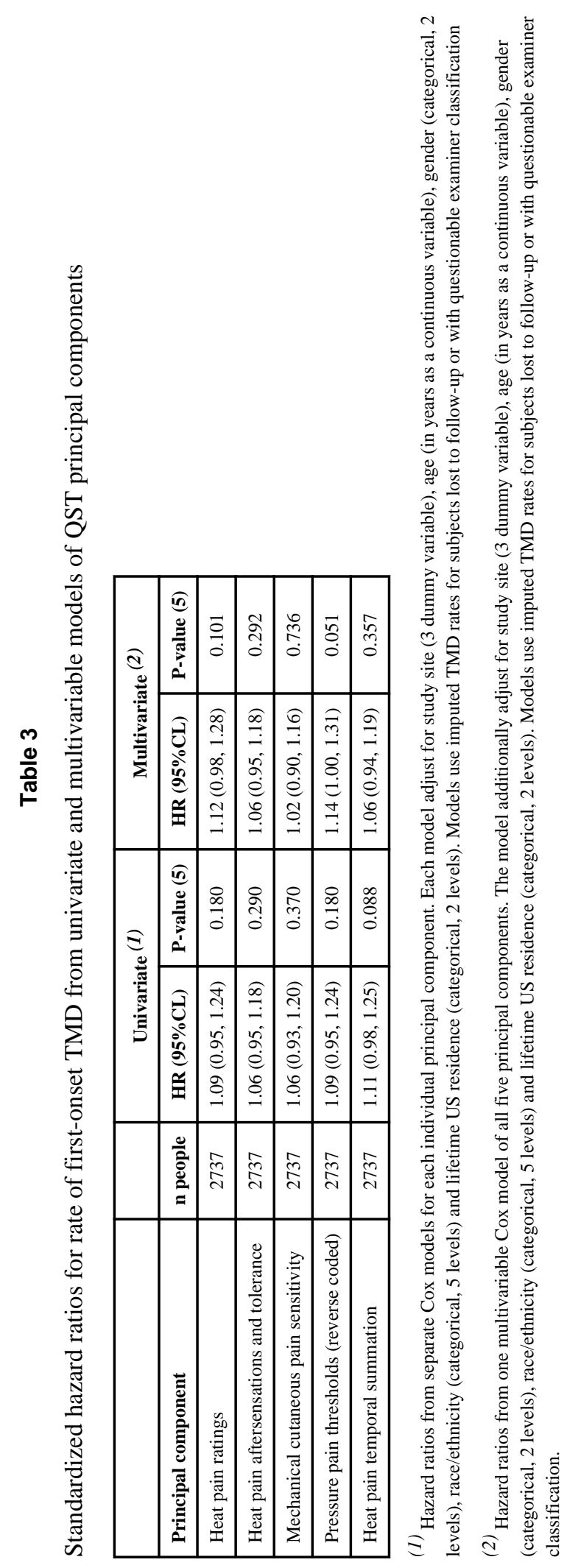

J Pain. Author manuscript; available in PMC 2014 December 01. 


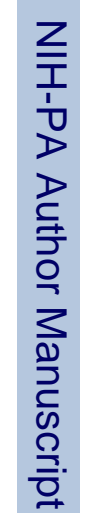

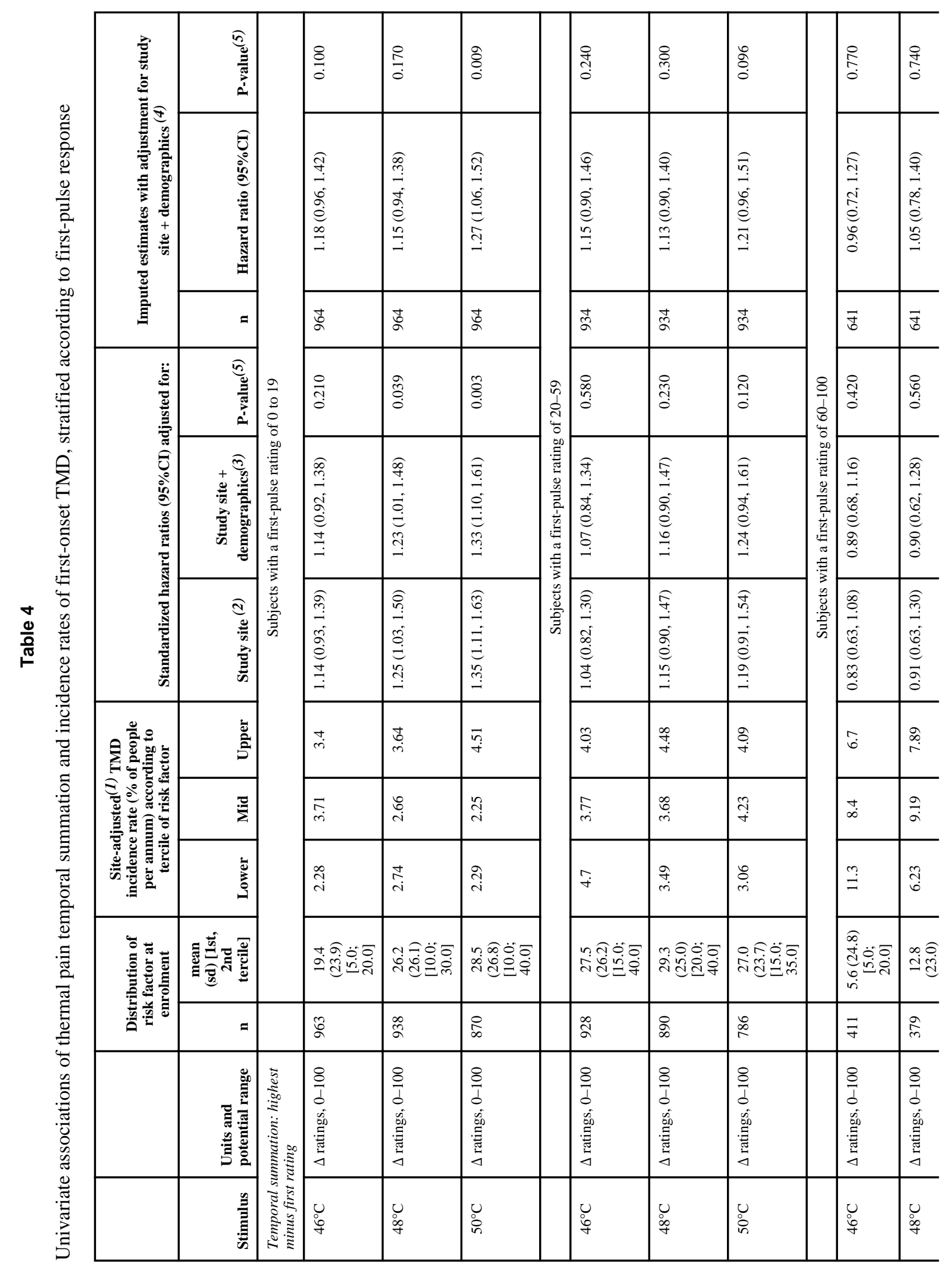

J Pain. Author manuscript; available in PMC 2014 December 01. 


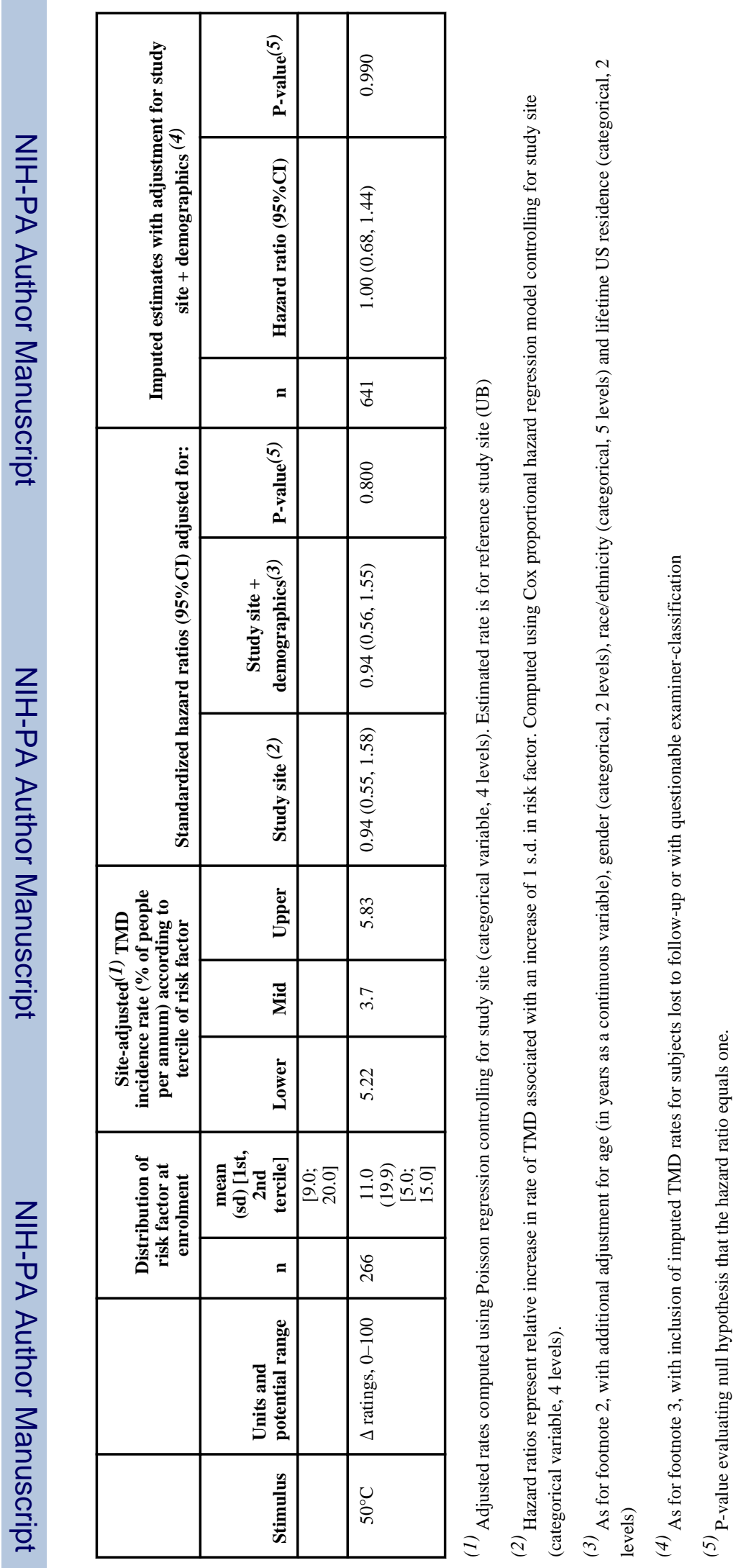

J Pain. Author manuscript; available in PMC 2014 December 01. 